\title{
Utilization of Cassava Starch in Copolymerisation of Superabsorbent Polymer Composite (SAPC)
}

\author{
Akhmad Zainal Abidin, Tiara Puspasari \& Hafis Pratama Rendra Graha \\ Department of Chemical Engineering, Faculty of Industrial Technology \\ Institut Teknologi Bandung, Jalan Ganesa 10 Bandung 40132, Indonesia \\ Email: zainal@che.itb.ac.id
}

\begin{abstract}
Cassava starch was used as the main chain in the copolymerization of a superabsorbent polymer composite (SAPC) based on acrylic acid and bentonite. The SAPC was synthesized through graft polymerization using nanosized bentonite as reinforcement. The variables in this experiment were: bentonite concentration, acrylic acid to starch weight ratio, concentration of initiator, and cross linker. The product was characterized using FTIR, SEM and TGA-DSC. The results show that the polymerization reactions involved processes of incorporating starch chains as polymer backbone and grafting acrylic acid monomers onto it. The use of cassava starch in the polymerisation produced a very short reaction time (10-15 minutes), which led to SAPC production with higher efficiency and lower cost. Bentonite interacts with monomers via hydrogen and weak bonding, thus improving the thermal properties of the product. The maximum absorbance capacity obtained was at an acrylic acid to starch weight ratio of 5 and a concentration of initiator, cross linker and bentonite of $0.5,0.05$ and 2 weight percent, respectively. The product is suitable for agricultural and medical applications as well as common superabsorbent polymer applications.
\end{abstract}

Keywords: cassava starch; bentonite; superabsorbent polymer composite; SAPC; acrylic acid; graft polymerization.

\section{$1 \quad$ Introduction}

Nowadays, natural polymers, which are biodegradable, draw great attention from both academic and industrialized circles all over the world as a result of environmental problems posed by the disposal of synthetic polymer waste. Therefore, the development of a range of biodegradable polymer-based products has become one of their main focuses. One of the practical approaches in making a biodegradable polymer is by replacing most synthetic materials in the polymer precursors with natural materials so that the resulting product is easier to degrade. In addition to degradability, other aspects-such as biocompatibility, renewability and toxicity of products-are also becoming key considerations for using natural materials as a substitute for synthetic materials.

Received August $13^{\text {th }}, 2013$, Revised March $8^{\text {th }}, 2014$, Accepted for publication June $25^{\text {th }}, 2014$.

Copyright (C) 2014 Published by ITB Journal Publisher, ISSN: 2337-5779, DOI: 10.5614/j.eng.technol.sci.2014.46.3.4 
Cassava starch as one of the most abundant agricultural commodities in Indonesia is a relatively cheap material that is easy to come by. In relation to the issues described above, cassava starch can be used as a substitute for a variety of synthetic polymer precursors because it is biodegradable, biocompatible, renewable and nontoxic. Indonesia, as a country with a high productivity of cassava starch, is suitable to develop cassava starch-based polymers.

Abidin [1] states that superabsorbent polymers (SAPs) are a hydrophilic material, able to absorb enormous amounts of water. They are commonly used as an absorbent fluid in baby diapers and sanitary napkins, as well as in other fields, such as medicine, agriculture and engineering. Today, almost all of the commercial SAPs are synthetic polymers that can hardly be degraded by the environment and hence the use of these products may lead to environmental problems as a result of waste disposal. In this research, one of the main SAP precursors, acrylamide [2], was replaced by starch because both have similar hydrophilic chemical properties. Therefore, the development of starch-based SAPs has a high potential for addressing environmental issues.

Another background of this research is that the utilization of plant products, especially cassava tubers, in Indonesian industry is not optimized yet, while Indonesia was the third largest exporter of cassava in the world in 2005 based on statistics from the Food and Agriculture Organization of the United Nations (FAO). Compared with other tubers, cassava has the highest productivity in Indonesia [3]. The utilization of cassava starch as a raw material for SAPs can increase the production as well as consumption level of cassava in Indonesia, as a result of which the agricultural sector can grow significantly. In addition, the cassava starch, which has a much lower price than acrylamide, is economically advantageous in the production of polymers.

Based on Hosseinzadeh's explanation [4], starch-based polymers generally have poor mechanical and thermal resistance. To overcome this, bentonite (a kind of phyllosilicates mineral) is used to reinforce the polymer. This is relatively cheap, so the chemical blending by means of graft copolymerization of acrylic acid, starch and bentonite in fabricating the superabsorbent composite can further reduce the production cost significantly and improve the properties of the superabsorbent material.

In this research, a superabsorbent polymer composite (SAPC) was synthesized, tested and analyzed using starch as the backbone chain, acrylic acid as the monomer, N,N-methylene bisacrylamide (MBA) as the cross linker, and ammonium persulphate (APS) as the initiator in the presence of nano-sized bentonite in an aqueous solution. Aspects investigated included the optimum synthesizing conditions. This research referred to previous research by Li [5], 
who successfully created a superabsorbent polymer composite with a high absorbance capacity, reaching $774 \mathrm{~g} / \mathrm{g}$ product, made from potato starch, acrylic acid and attapulgite. Because the productivity of cassava in Indonesia is much higher than that of potatoes, in this research the SAPC was made from cassava starch.

\section{$2 \quad$ Materials and Method}

The materials for manufacturing SAPC consisted of: cassava starch (commercial grade, Rose brand, Indonesia) used as purchased; acrylic acid (AA, chemically pure, Merck, Germany) used as purchased and neutralized $40 \%$ with sodium hydroxide; N,N-methylenebisacriyamide (MBA, Merck, Germany) used as purchased; ammonium persulphate (APS, chemically pure, Merck, Germany) used as purchased; and sodium-bentonite (GTC4, powder, drilling mud quality, PT. Mahesa Rekatama, Indonesia) dried at $95^{\circ} \mathrm{C}$ and milled for 12.5 hours.

A series of samples with different amounts of bentonite, cross linker, initiator, starch and acrylic acid with $40 \%$ degrees of neutralization were prepared with the following procedure: tapioca flour and water were mixed together with a ratio of 1:20 and put into a four neck flask equipped with a magnetic stirrer, thermometer and nitrogen line. The slurry was heated at $90^{\circ} \mathrm{C}$ for 30 minutes and then chilled to a temperature of $60-65^{\circ} \mathrm{C}$. The APS was added into the mixture and stirred for 15 minutes. A mixture of partially neutralized AA, MBA and bentonite was then added to the system. The total concentration of the water in the reactor was $75 \mathrm{w}-\%$. The system was heated slowly to $70^{\circ} \mathrm{C}$ until a gel block product was obtained that could not be stirred anymore. Then the resulting product was washed with ethanol and distilled water and dried at a temperature of $70^{\circ} \mathrm{C}$ to a constant weight. The dried product was milled and screened to achieve a particle size in the range of 20-80 mesh.

The IR spectra of the superabsorbent composite were recorded on a FTIR machine (Prestige 21 Shimadzu, Japan) using $\mathrm{KBr}$ pellets. A thermal stability study of the dry samples was performed on a simultaneous thermal analyzer (Linseis STA PT-1600), with a temperature range of room temperature- $550^{\circ} \mathrm{C}$ at a heating rate of $10^{\circ} \mathrm{C} / \mathrm{min}$. The morphology of the samples was studied through analysis on a scanning electron microscope (JSM-6360LA, jEOL, Japan) at 40,000 magnification. 


\section{$3 \quad$ Results and Discussion}

\subsection{IR Spectra}

The IR spectra of the cassava starch and the SAPC are presented in Figure 1. A comparison of the spectra of the cassava starch and the SAPC revealed that the hydroxyl groups on the cassava starch, with peaks at 527.54 and $576.73 \mathrm{~cm}^{-1}$, were not found in the SAPC's spectra. This could be due to the fact that the ring of starch was opened and $-\mathrm{COH}$ had to be changed to $* \mathrm{COH}$ and then graft polymerization between the $* \mathrm{COH}$ groups on the starch and the acrylic acid monomers took place [6]. ${ }^{*} \mathrm{COH}$ is a radical active site on the starch backbone made by the initiator.

Figure 1 also shows that the peak at $1641.45 \mathrm{~cm}^{-1}$, attributed to carbonyl groups $(\mathrm{C}=\mathrm{O})$ on the cassava starch, was also not found in the SAPC spectra. This may happen when in the polymerization process most of the carbonyl groups of the starch break as the $\mathrm{C}-\mathrm{O}$ groups bond and attach to each other to form longer chains of starch. This phenomenon was also reported in another experiment [7].

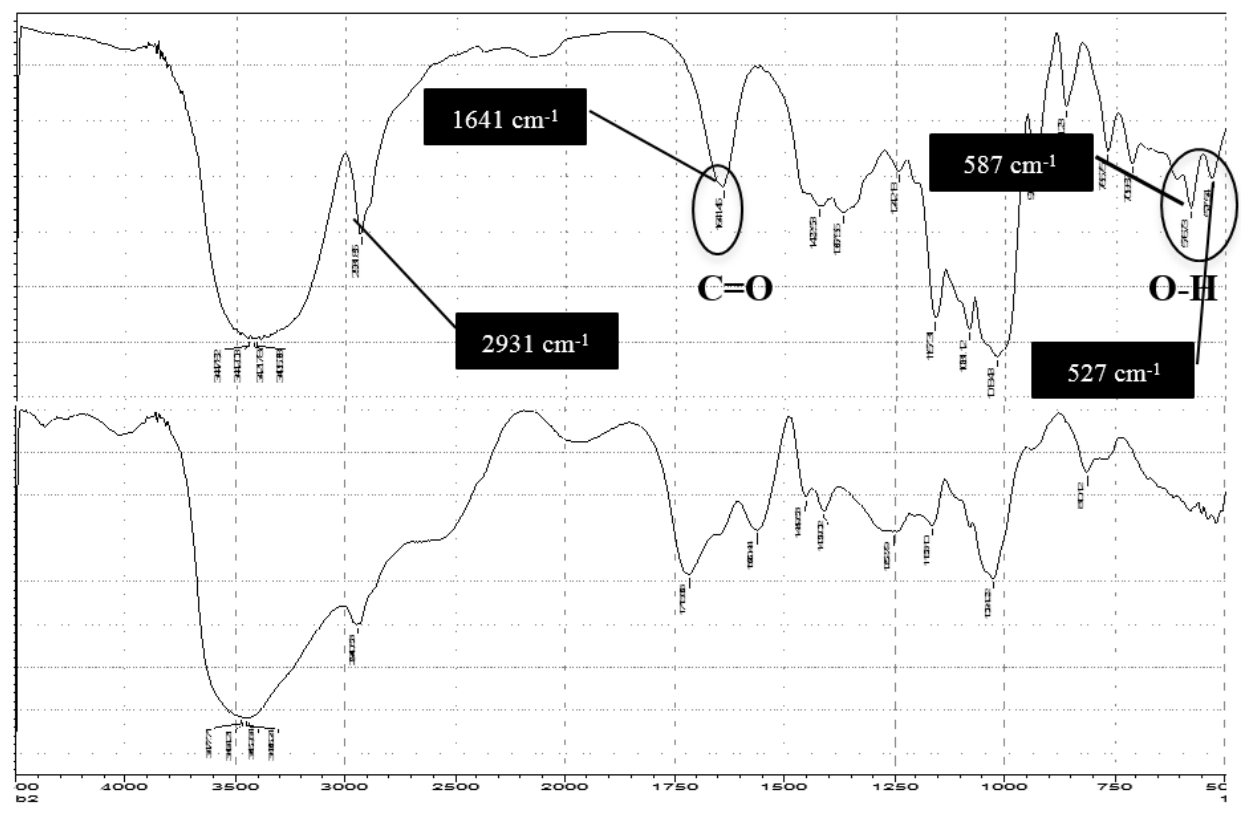

Figure 1 IR spectra of cassava starch (above) and SAPC (below). 


\subsection{Thermal Stability}

The thermal analysis result of the sample with the best absorbency $(997.7 \mathrm{~g}$ $\mathrm{H}_{2} \mathrm{O} / \mathrm{g}$ product) is shown in Figure 2. Components of the sample were bentonite, MBA, APS, at concentrations of $2 \%, 0.05 \%, 0.5 \%$ respectively, while the AA/starch ratio was 5. The glass transition temperature $\left(T_{g}\right)$ of the SAPC sample was determined by DSC and had a value of around $154.6^{\circ} \mathrm{C}$. This result is a typical value, similar to that of the SAPC that was produced by Gao [8] with $\mathrm{T}_{\mathrm{g}}<200^{\circ} \mathrm{C}$.

The TGA curve shows that the degradation process began at a temperature of around $100^{\circ} \mathrm{C}$. At the end of the analysis, at $550^{\circ} \mathrm{C}$, sample mass loss was $58 \%$ Compared to similar products with the same relative absorbance capacity as described by Li [5], this SAPC product had a slightly higher thermal resistance. Li's product underwent a mass loss of up to $59 \%$ at a temperature of $450{ }^{\circ} \mathrm{C}$, while this SAPC experienced a mass loss of $51.8 \%$ at the same temperature and $58 \%$ at the much higher temperature of $550^{\circ} \mathrm{C}$. This is mainly due to the use of cassava starch and nano-sized reinforcement particles in the SAPC, which are much smaller than the micron particles used by Li. This condition makes that the particles can easily be intercalated in the polymer by a much stronger bond so it has a higher thermal resistance.

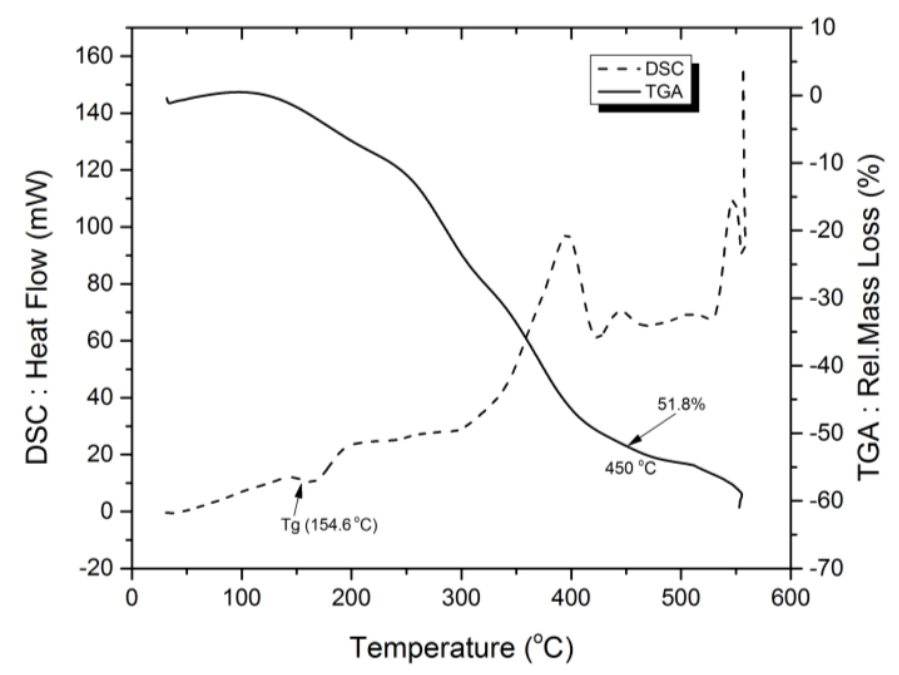

Figure 2 TGA-DSC curve of SAPC.

\subsection{Absorbance Capacity}

The absorbance capacity was measured by soaking the product in distilled water until it reached swelling equilibrium. The swollen samples were then separated 
from the unabsorbed water by filtering over a 100 -mesh screen. The water absorbency was determined by calculating the difference of mass between the swollen and the dry sample and dividing the result by the mass of the dry sample.

Effect of Bentonite Concentration. From the displayed graph (Figure 3) it can be seen that the maximum absorbance capacity was obtained at a bentonite concentration of $2 \%$, though this value did not differ significantly from that for the bentonite concentrations of 1.5 and $2.5 \%$.

Between the bentonite concentrations of 0 and $2 \%$ there was an upward trend of absorbance capacity because the cross-link density of the superabsorbent polymer increased along with the increase in bentonite concentration of the reinforcement, resulting in a structure that is capable of absorbing more water. When the bentonite concentration increased above $2 \%$, the absorbance capacity steadily became lower because the composite was denser and the volume of pores contained in it was smaller. This led to less water absorbed due to the limited surface area of the composite, as stated in a previous research by Abidin [2].

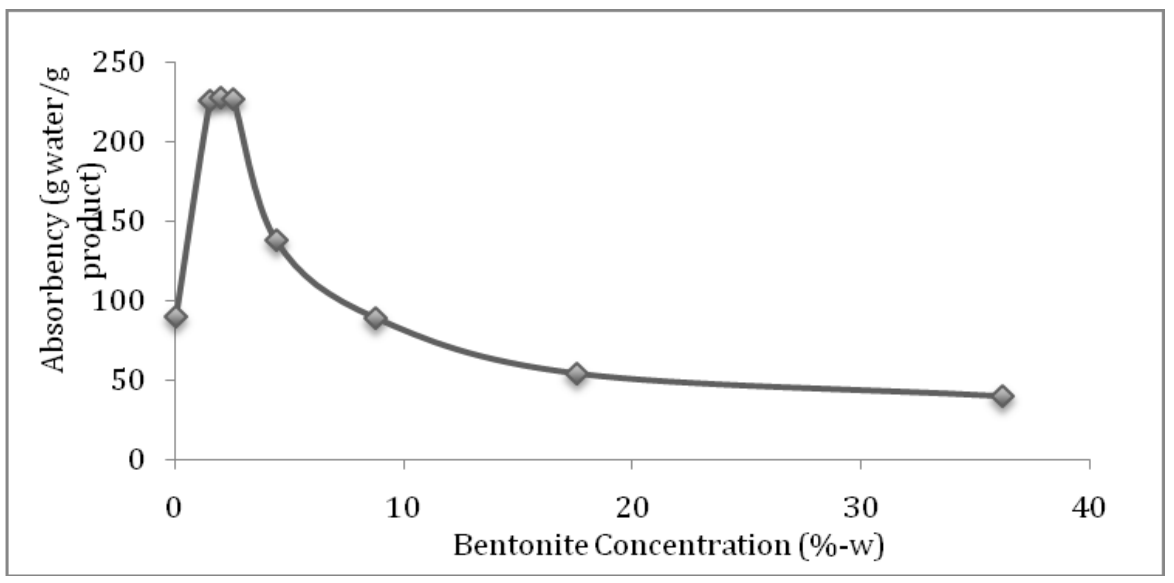

Figure 3 Absorbance capacity of SAPC at various bentonite concentrations for an AA/starch ratio of 28.5 , and concentrations of cross linker and initiator of $0.3 \%$ and $1.3 \%$, respectively.

Effect of Mass Ratio of AA to Starch. The mass ratio of AA to starch is an important variable of analysis because it determines the optimum amount of starch as backbone chains of the composite that results in the maximum absorbance capacity. In order to determine the optimum value, 4 runs with different ratios of AA to starch were carried out. The results are shown in Table 1. 
Table 1 Absorbance capacity of SAPC at various ratios of AA/starch for concentrations of bentonite, initiator, and crosslinker of $1.5 \%, 1.3 \%$ and $0.4 \%$ respectively.

\begin{tabular}{cc}
\hline AA/starch ratio & Absorbance capacity $\left(\mathbf{g ~ H}_{\mathbf{2}} \mathbf{O} / \mathbf{g}\right.$ product $)$ \\
\hline 4 & 212.7 \\
5 & 222.9 \\
6 & 192.0 \\
7 & 191.4 \\
\hline
\end{tabular}

Table 1 shows that the maximum absorbance capacity of the SAPC occurred at an AA/starch ratio of 5 . This value was not significantly different for the other variations, although the influence of the difference in ratio was quite significant. The products with a ratio of 5 had a higher absorbance capacity than the products with a ratio of 4 because the effective cross-linking density is probably lower than the nominal cross-linking density at a low total monomer concentration in the preparation of cationic hydrogel, as described by Baker in [9]. However, there is a decline of absorbance capacity when the number of monomers is too high. Reyes [10] has found that this phenomenon may be due to an increase in the homopolymer percentage of the polyacrylic acid (PAA), which in turn results in an increase in soluble materials at a fixed cross-linking density. A similar analysis and similar observations have also been reported by others $[5,11,12]$.

Effect of cross linker concentration. The effect of the cross linker concentration on the absorbance capacity of the composite can be seen in Table 2. As already described in the previous sub-chapter, an increase in cross links will generally decrease the absorbance capacity. At a concentration below $0.05 \%$, the absorbance capacity was low because the formed composites were not strong enough to absorb a great amount of water, whereas at higher concentrations the absorbance capacity dipped as a result of a denser composite with a smaller volume of pores [2].

Table 2 Absorbance capacities of SAPNC at various cross linker concentrations for an $\mathrm{AA} / \mathrm{starch}$ ratio of 5 and concentrations of bentonite and initiator of 1.5 and $1.3 \%$ respectively.

\begin{tabular}{cc}
\hline Cross linker concentration (w-\%) & Absorbance capacity $\left(\mathbf{g ~ H}_{2} \mathbf{O} / \mathbf{g}\right.$ product) \\
\hline 0.02 & 279.5 \\
0.05 & 380.3 \\
0.08 & 278.8 \\
0.10 & 275.8 \\
0.40 & 222.9 \\
\hline
\end{tabular}


Effect of Initiator Concentration. In Table 3 it can be seen that the maximum absorbance capacity occurred at a cross linker concentration of $0.5 \%$. Below this point, the absorbance capacity was low because the amount of free radicals formed was small, which leads to low grafting efficiency, similar to Willet's result [13]. However at higher concentrations, the amount of free radicals formed is too large, which leads to fast initiation, which in turn would obviously produce many low molecular weight copolymers with a low absorbance capacity. A higher initiator concentration also leads to a greater formation of PAA $[5,14,15]$ so that the monomers, which are supposed to be bound as copolymers, are reduced.

Table 3 Absorbance capacity of SAPC at various initiator concentrations for an AA/starch ratio of 5 and concentrations of bentonite, cross linker and initiator of $2,0.05$, and $0.5 \%$, respectively.

\begin{tabular}{cc}
\hline Initiator concentration (w-\%) & Absorbance capacity $\left(\mathbf{g ~ H}_{\mathbf{2}} \mathrm{O} / \mathbf{g}\right.$ product) \\
\hline 0.3 & 561.7 \\
0.5 & 997.7 \\
0.8 & 403.2 \\
1.3 & 380.3 \\
\hline
\end{tabular}

Rate of Absorbance. Analysis of the absorbance rate was carried out by measuring the mass of swollen product in a variety of soaking times. Before measurement, the product was dried at a constant temperature of $70^{\circ} \mathrm{C}$ and then filtered over a 20-80 mesh screen. The results are depicted in Figure 4.

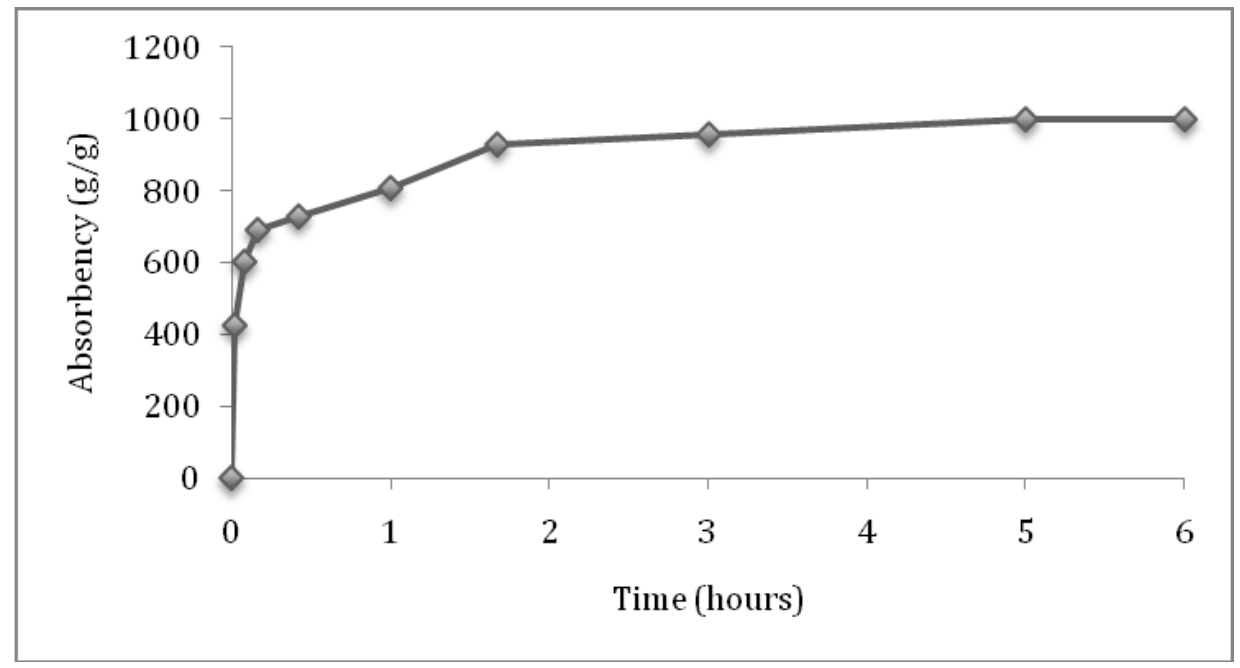

Figure 4 Absorbance rate of SAPC. 
The absorbance measurements show that the absorbance capacity was proportional to the soaking time. The resulting SAPC could absorb water in a relatively short time. At a time of 30 minutes, the product was $75 \%$ saturated by water $(750 \mathrm{~g} / \mathrm{g})$. The minimum soaking time to obtain maximum absorbance capacity was about 5 hours. Referring to the research by Omidian [16], a superabsorbent polymer that can reach $60 \%$ from saturated condition in less than 3 hours indicates that the polymer has large enough pores and can be concluded to be a "porous hydrogel".

Water retention. The water retention of the SAPC was determined by heating the swollen sample in an oven at certain temperatures. Figure 5 shows the water retention of the SAPC as a function of time for temperatures of 60 and $100^{\circ} \mathrm{C}$. The sample heated at a temperature of $60^{\circ} \mathrm{C}$ experienced a loss of water by $50 \%$ after 20 minutes and it took 45 minutes to release all the water contained. Meanwhile, the sample heated at a temperature of $100^{\circ} \mathrm{C}$ required a much shorter time to experience a loss of $50 \%$ of water ( 15 minutes) and took 30 minutes to release all water contained.

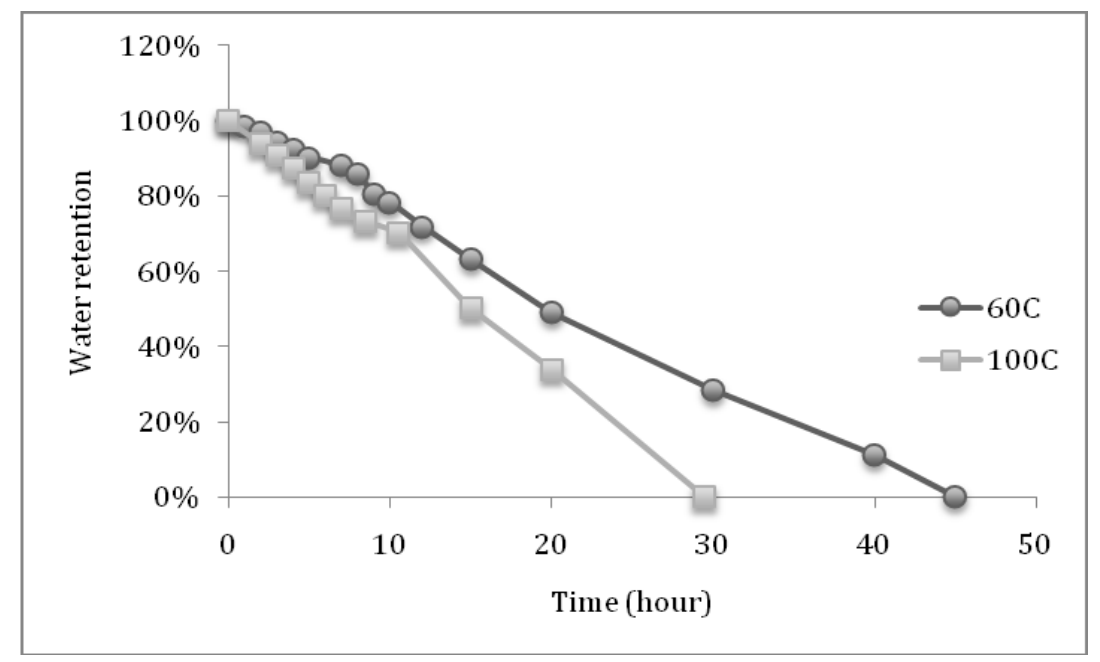

Figure 5 Water retention of swollen SAPC at 60 and $100^{\circ} \mathrm{C}$.

The phenomenon of water being released from the composite structure at high temperatures is caused by the breaking of both weak and hydrogen bonds between water molecules and polymer chains, so that the water is released easily. It is also related to the process of phase change of water into vapor, where the pressure is higher and it becomes easier to move as a result of the increased kinetic energy. 
SEM analysis. SEM images of the product are presented in Figure 6. It can be seen that at the same magnification both of the images are very different. The product with minimum absorbency (Figure 6(a)) had a dense surface almost without cracks, while the product with maximum absorbency (Figure 6(b)) had a large number of cracks spread evenly across its surface.

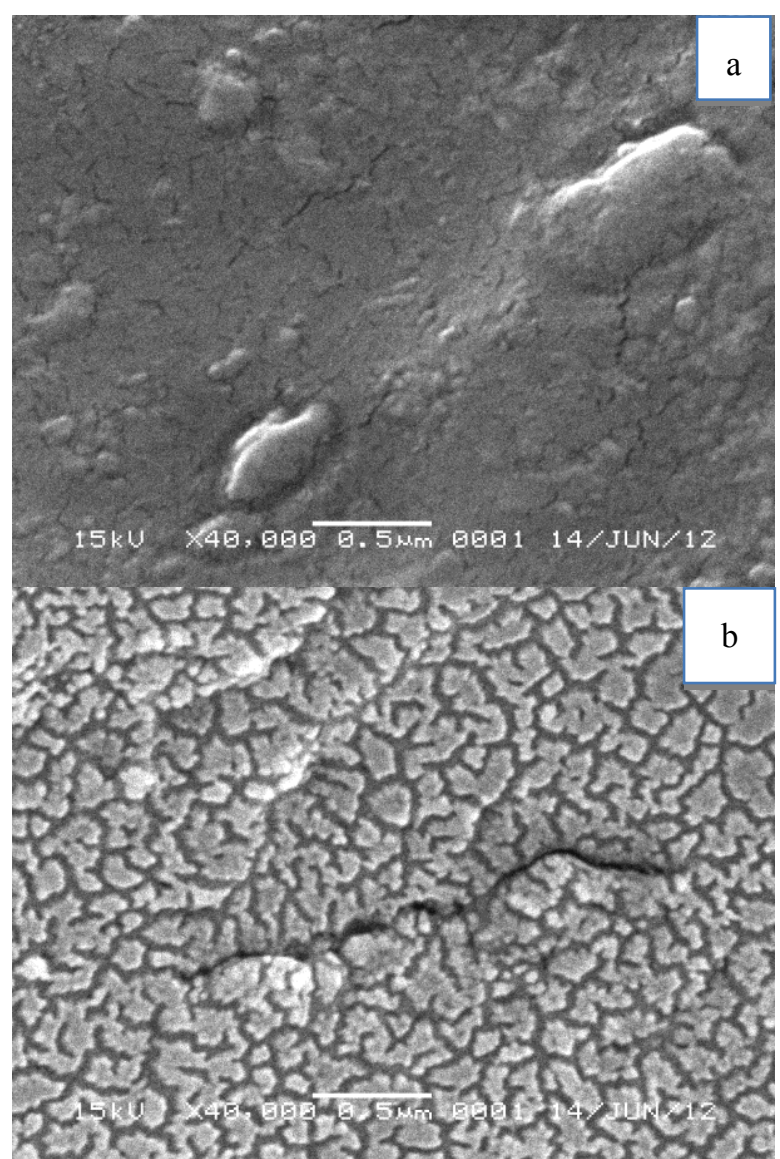

Figure 6 SEM images of SAPC with lowest (a) and highest (b) absorbency (magnification at 40,000).

Wang [17] has found that cracks are one out of three types of pores that determine the total porosity of a material. In the case of a superabsorbent polymer, cracks created on the surface and in the bulk of the polymer allow water to diffuse by capillary forces. The outermost dry layer of granular particles is first moistened upon contact with water, resulting in two phases of polymer, partially swollen and dry. The diffusion of water continues through the 
partially swollen layer towards the core. Thus, the cracks in superabsorbent materials are the most important factor for determining the absorbance capacity.

A product without cracks will have a very low absorbance capacity due to the limited amount of water that diffuses into the matrix created by the small surface area. In a product with maximum absorbency, the greater porosity makes the water enter very easily and interact within the matrix so that the amount of absorbed water is larger. In addition to particle size, it was shown in this study that the number and the size of the cracks on the surface of the composite matrix is also proportional to the rate of absorbance, as more and more and larger cracks exist within the surface that will make the water move more quickly through the matrix.

\subsection{The Short Reaction Time}

The process of synthesizing SAPC followed previously described procedures [5] in which SAPC was made from potato starch. It was reported that by using the same cross linker and initiator, the reaction time required to produce the final gel block product was about 3 hours [5], but synthesizing the cassava starch-composite with the same procedure took only about 10-15 minutes. There are many possible causes underlying this phenomenon, but the most logical reason is the difference in composition between the starches. The amount of amylopectin contained in cassava starch is about $84 \%$, while in potato starch it is $79 \%$ (based on Meyer [18]). It is clear that a higher amount of amylopectin leads to a softer gel with less cross links within the starch [19]. This allows the radical initiators to react with the starch chains easily, resulting in longer chains. This leads to rapid polymerization when the monomer is added, thus the final gel block is formed very fast. Even though the amount of amylopectin contained in cassava starch is slightly higher than in potato starch, the significant difference in molecular weight between amylopectin and amylose results in a significant difference in reaction time.

\section{Conclusion}

SAPC can be made from cassava starch through a radical polymerization reaction with acrylic acid. Utilizing natural resources like starch and bentonite in the production of this superabsorbent material produced a very short reaction time (10-15 minutes), which means SAPC production with higher efficiency and lower cost. Additionally, this makes the technique quite environmentally friendly. The maximum absorbance capacity of $1000 \mathrm{~g} / \mathrm{g}$ SAPC was obtained at a weight ratio of acrylic acid to starch of 5 and concentrations of bentonite, APS and MBA of 2, 0.5 and $0.05 \mathrm{w}-\%$, respectively. This novel superabsorbent composite with an excellent rate of absorbency and water retention can be 
useful as an absorbent material for baby diapers and agricultural and medical applications.

\section{References}

[1] Abidin, A.Z., Puspasari, T. \& Nugraha, W.A., Polymers for Enhanced Oil Recovery Technology, Procedia Chemistry, 4, pp. 11-16, 2012.

[2] Abidin, A.Z., Noezar, I. \& Ridhawati, Synthesis and Characterization of Superabsorbent Polymer Composites Based on Acrylic Acid, Acrylamide and Bentonite, Indonesian Journal of Material Science, 12(2), pp.114119, 2011.

[3] Abidin, A.Z., Devi, C. \& Adeline, Development of Wet Noodles Based on Cassava Flour, J. Eng. Technol. Sci., 45(1), pp. 97-111, 2013.

[4] Hosseinzadeh, H., Sadeghzadeh M. \& Babazadeh, M., Preparation and Properties of Carrageenan-g-Poly(Acrylic Acid)/Bentonite Superabsorbent Composite, Journal of Biomaterial and Nanotechnology, 2, pp. 311-317, 2001.

[5] Li, A., Zhang, J. \& Wang, A., Utilization of Starch and Clay for The Preparation of Superabsorbent Composite, J. Biotech, 98, pp. 327-332, 1992.

[6] Wu, J.H., Lin, J.M. \& Zhou, M., Synthesis and Properties of starch-Graft Polyacrylamide/Clay Superabsorbent Composite, Macromolecular Rapid Communication, 21, pp. 1032-1034, 2000.

[7] Mehr, M.J.Z. \& Kabiri, K., Superabsorbent Polymer Materials: A Review, Iranian Polymer Journal, 17(6), pp. 451-477, 2008.

[8] Gao, D., Superabsorbent Polymer Composite (SAPC) Materials and their Industrial and High-Tech Applications, Dissertation, Freiberg University, Freiberg-Germany, 2003.

[9] Baker, J.P., Hong, L.H., Blanch, H.W. \& Pransnitz, J.M., Effect of Initial Total Monomer Concentration on the Swelling Behavior of Cationic Acrylamide-Based Hydrogels, Macromolecules, 27, pp. 1446-1454, 1992

[10] Reyes, Z., Clark, C.F., Comas, M., Russell, C.R. \& Rist, C.E., Continuous Production of Graft Copolymers of Starch with Acrylamide and Acrylic Acid by Electron Preirradiation, Nuclear Applications, 6, pp. 509-517, 1969.

[11] Chen, J.W. \& Zhao, Y.M., Relationship Between Water Absorbency and Reaction Conditions in Aqueous Solution Polymerization of Polyacrylate Superabsorbents, Journal of Applied Polymer Science, 75, pp. 808-814, 2000.

[12] Lee, W.F. \& Yeh, P.L., Effect of Initial Total Monomer Concentration on the Swelling Behavior of Crosslinked Poly(Sodium Acrylate) in Aqueous Salt Solution, Journal of Applied Polymer Science, 64, pp. 2371-2380, 1997. 
[13] Willett, J.L. \& Finkenstadt, V.L., Preparation of Starch-GraftPolyacrylamide Copolymers by Reactive Extrusion, J. Polym, 43(10), pp. 1666-1674, 2000.

[14] Nakason, C., Wohmang, T., Kaesaman, A. \& Kiatkamjornwong, S., Preparation of Cassava Starch-Graft-Polyacrylamide Superabsorbents and Associated Composites by Reactive Blending, Thailand Carbohydrate Polymers, 81, pp. 348-357, 2010.

[15] Athawale, V.D. \& Lele, V., Factors Influencing Absorbent Properties of Saponified Starch-G-(Acrylic Acid-Co-Acrylamide), Journal of Applied Polymer Science, 77, pp. 2480-2485, 2000.

[16] Omidian, H., Rocca, J.G. \& Park, K., Advances in Superporous Hydrogels. Journal of Controlled Release, 102, pp. 3-12, 2005.

[17] Wang, Z., Kulkarni, A., Deshpande, S., Nakamura, T. \& Herman, H., Effects of Pores and Interfaces on Effective Properties of Plasma Sprayed Zirconia Coatings, Acta Materialia, 51, pp. 5319-5334, 2003.

[18] Meyer, K.H., Berufeld, P. \& Hohenemser, W., Recherches sur l'amidon VI. Les acétates et les nitrates d'amylose et d'amylopectine, Helv. Chim. Acta, 23(1), pp. 885-890, 1940.

[19] Megan E., Starch, Central Washington University, http://www.cwu.edu/ $\sim$ geed/440/Starches\%20Megan\%20Erickson.ppt $\left(25^{\text {th }}\right.$ October 2012). 